\title{
REFLEXÕES SOBRE AS DIFICULDADES APRESENTADAS NA APRENDIZAGEM DA ÁLGEBRA POR ESTUDANTES DA $7^{a}$ SÉRIE ${ }^{1}$
}

\author{
Katia Henn Gil \\ Professora da Rede Municipal de Ensino - SMED Viamão \\ katiahenngil@gmail.com
}

Vera Lucia Felicetti

Professora do Programa de Pós-Graduação em Educação. Centro Universitário La Salle UNILASALLE - CANOAS/RS

verafelicetti@ig.com.br

\begin{abstract}
Resumo
Neste artigo apresenta-se um estudo que tem por objetivo identificar as dificuldades na aprendizagem de Álgebra e algumas causas dessas dificuldades presentes nas atividades realizadas por alunos da $7^{\text {a }}$ série do Ensino Fundamental, sujeitos deste estudo. O estudo foi orientado por uma abordagem metodológica de cunho quali-quanti. Para a coleta de dados foram realizadas observações na turma em questão e aplicadas atividades envolvendo os conteúdos algébricos trabalhados pela docente da turma. Dentre os fatores relacionados às dificuldades na aprendizagem, observou-se que a interpretação de problemas algébricos, que exige uma tradução da linguagem corrente para a linguagem simbólica, apresenta-se como obstáculo, o que representa dizer que muitas vezes a não compreensão da linguagem apresentada no problema, dificulta a tradução para a linguagem algébrica. Outro obstáculo encontrado na investigação consiste na falta de pré-requisitos em Aritmética o que desencadeia dificuldades na aprendizagem da Álgebra, uma vez que esta necessita da primeira para a resolução das atividades nela propostas.
\end{abstract}

Palavras-chave: Aprendizagem. Álgebra. Educação Matemática.

\begin{abstract}
This paper presents a study that aims to identify the difficulties in learning Algebra and some causes of these difficulties present in activities performed by 7th grade of elementary school. The study was guided by a methodological approach of qualitative and quantitative nature For data collection was used observation in the class in focus and applied activities involving algebraic contents worked by the class' teacher. Among the factors related to learning difficulties, it was observed that the interpretation of algebraic problems, which requires a translation in common language as the symbolic language, is presented as an obstacle, which is that the student has difficulty in comprehension of language presented in the problem, immediately associate it with algebraic language. Another obstacle observed was the lack of prerequisites in arithmetic which triggers difficulties in learning Algebra, since it needs from the first to the resolution of the activities proposed there in.
\end{abstract}

Keywords: Learning. Algebra. Mathematics Education.

\footnotetext{
${ }^{1}$ Atualmente a $7^{\mathrm{a}}$ série corresponde ao $8^{\circ}$ ano do Ensino Fundamental. Neste artigo será usada $7^{\mathrm{a}}$ série, pois essa turma ainda encontrava-se no regime de oito anos para o Ensino Fundamental quando desta investigação.
} 


\section{INTRODUÇÃO}

Para Lins; Gimenez (1997, p.137), “a álgebra consiste em um conjunto de afirmações para as quais é possível produzir significado em termos de números e operações aritméticas, possivelmente envolvendo igualdade e desigualdade”. Logo, para produzir significados dentro do contexto algébrico, há a necessidade não somente do desenvolvimento do pensamento aritmético, mas também do pensamento algébrico, associando a isso abstrações e generalizações. Nesta direção, entende-se a Álgebra como parte da Matemática que trabalha a generalização e abstração, representando quantidades através de símbolos.

A Álgebra tem muitas aplicações nas diferentes áreas do conhecimento. É usada na medicina quando se calcula a dosagem de medicamentos; na biologia auxilia no cálculo de população de bactérias, também é usada nos programas de computadores na representação de fórmulas e propriedades. Ainda é usada no dia a dia, quer seja ele escolar ou não. No primeiro, por exemplo, o aluno pode calcular a nota faltante para completar a sua média trimestral. No segundo, ao realizar o cálculo no orçamento doméstico ou para a compra de algum bem. A Álgebra mostra-se útil como estratégia de resolução de problemas, uma vez que facilita a organização do cálculo. Logo, um dos objetivos do estudo da Álgebra é possibilitar ao aluno a compreensão dos seus conceitos, utilizando-os em situações, tais como a relação entre quantidades, permitindo encontrar um valor desconhecido e generalização de padrões. Enfim, que o aluno perceba a Álgebra como uma aliada na resolução de problemas em diferentes contextos.

Nesta direção, observa-se que estudar álgebra constitui-se não somente importante na vida escolar do aluno, mas também, para o manejo de cálculos nas diversas situações do dia a dia fora da sala de aula. Assim, aprender Álgebra vai muito além de repetir exercícios de algoritmos, ou seja, aprender Álgebra significa resolver problemas utilizando representações e dando significados a elas. No entanto, o que se observa em avaliações de desempenho referente à resolução de conteúdos algébricos, sinaliza que os alunos apresentam dificuldade no seu entendimento devido a média que apresentam. (INEP, 2011a).

Os resultados da Prova Brasil, referente aos anos finais do Ensino Fundamental mostram que a média dos estudantes brasileiros está em um nível seis de desenvolvimento, em uma escala que vai até doze (INEP, 2011a). Na descrição dos 
níveis da escala de desempenho de Matemática estabelecido pelo Sistema de Avaliação da Educação Básica - SAEB, os alunos no nível seis ainda não possuem as habilidades descritas no Tema III, no qual fazem parte as do contexto algébrico (INEP, 2011b). Sendo assim, de acordo com os critérios avaliativos do SAEB, muitos dos alunos brasileiros da $8^{\mathrm{a}}$ série, atual $9^{\circ}$ ano do Ensino Fundamental não possuem habilidades para a resolução de problemas que envolvem conteúdos algébricos. Isto indica que os alunos têm dificuldades tais como: identificar uma expressão algébrica que expressa uma regularidade observada em sequências e identificar uma equação ou uma inequação de primeiro grau que expressa um problema. Diante de tais resultados observa-se que as habilidades necessárias para resolver problemas envolvendo conteúdos algébricos não foram desenvolvidas. Ao encontro do acima descrito, nos Parâmetros Curriculares Nacionais - PCN encontra-se que "a ênfase que os professores dão a esse ensino não garante o sucesso dos alunos, a julgar tanto pelas pesquisas em Educação Matemática como pelo desempenho dos alunos nas avaliações que têm ocorrido em muitas escolas". (BRASIL, 1997, p. 115).

Outro aspecto preocupante que está estritamente ligado às dificuldades apresentadas é o fato de o aluno detestar a Matemática. Entende-se que a Matemática traz consigo um formalismo que, aliado à dificuldade de abstração faz com que o aluno se distancie de seu estudo, até porque diversas vezes os conceitos e procedimentos apresentados não são entendidos de imediato e, talvez, nem ao longo do processo de ensino e aprendizagem, fazendo com que o aluno se desmotive para seu estudo. É importante ser considerado, também, que não raro alguns alunos chegam à escola com a ideia de que a Matemática é muito difícil. A preocupação com a aprendizagem de Matemática faz parte de debates educacionais tanto em âmbito nacional quanto internacional, uma vez que se procura por alternativas que possam diminuir o baixo aproveitamento dos alunos em Matemática. Existe um cuidado para que o ensino de Matemática seja eficaz e mostre resultados melhores dos que são apresentados hoje. De acordo com essa ideia, Onuchic e Allevato (2004, p.214) afirmam que "[...] gente de todo o mundo está trabalhando na reestruturação da Educação Matemática. Ensinar bem Matemática é um empenho complexo e não há receitas fáceis para isso. Não há um caminho único para se ensinar e aprender Matemática”.

Diante dos aspectos acima apresentados, em especial aos conteúdos relacionados a Álgebra da $7^{\mathrm{a}}$ série do Ensino Fundamental, este artigo apresenta em sua sequência a 
metodologia usada no delineamento da pesquisa. Seguindo a análise dos resultados e as considerações finais.

\section{METODOLOGIA}

Este artigo apresenta um estudo que teve por objetivo identificar as dificuldades na aprendizagem de Álgebra em atividades realizadas por alunos da $7^{\mathrm{a}}$ série do Ensino Fundamental. O estudo em foco realizou-se no ano de 2007, em uma escola da rede privada de ensino localizada na cidade de Porto Alegre - RS e é fruto de uma dissertação de Mestrado em Educação Matemática.

Este trabalho foi orientado por uma abordagem metodológica de cunho qualiquanti. De acordo com Flick (2004), a pesquisa qualitativa e a quantitativa não são opostos incompatíveis que não devam ser combinados. Elas se complementam. Neste trabalho o enfoque quantitativo versou sobre a quantificação dos resultados referentes à resolução dos exercícios dos alunos. Já o qualitativo voltou-se à análise dos dados descritos nas observações realizadas. Essa combinação, quali-quanti, foi orientada devido ao entendimento da importância de coletar o maior número de dados possíveis capazes de contribuir para uma melhor identificação acerca das dificuldades apresentadas pelos alunos no que concerne ao entendimento de conteúdos algébricos durante atividades de sala de aula.

Foi escolhida, por conveniência, uma $7^{\text {a }}$ série do Ensino Fundamental, na qual as aulas de Matemática foram observadas pela pesquisadora, bem como foram aplicadas algumas atividades para os 32 alunos da turma em questão, relacionadas ao conteúdo algébrico que estava sendo desenvolvido pela professora regente da turma. As atividades foram realizadas no segundo semestre, após o estudo pelos alunos dos conceitos algébricos contidos nas atividades. Os alunos foram identificados ao longo do trabalho em $A_{1}, A_{2}$ e assim sucessivamente até o $A_{32}$ e, nos diálogos, a professora foi identificada por $\mathrm{P}$.

A escolha pela $7^{a}$ série é justificável devido à maior ênfase dada ao estudo da Álgebra.

Para este estudo, os dados foram coletados através dos seguintes procedimentos:

- Observações semanais da turma durante um pouco mais de dois meses. 
Essas observações nos permitiram perceber a postura dos alunos frente às atividades propostas pela professora, assim como, a participação nas discussões realizadas no desenvolvimento da aula.

- Resolução de atividades aplicadas pelo pesquisador.

Os alunos resolveram algumas atividades elaboradas pela pesquisadora e outras por ela adaptadas e/ou retiradas de livros didáticos, as quais foram acordadas com o conteúdo desenvolvido pela professora regente. Exercícios propostos pela professora também foram analisados neste trabalho.

Na sequência é apresentada a análise oriunda das observações em aula e das atividades realizadas pelos alunos.

\section{DIFICULDADES DOS ALUNOS NO CONTEXTO DA SALA DE AULA}

Durante o acompanhamento da turma pesquisada, observando o processo de ensino e aprendizagem desenvolvido em sala de aula, foi possível perceber a postura dos alunos frente à prática pedagógica desenvolvida pela professora. Com uma aula dinâmica, diversificada e permeada de atividades investigativas e, utilizando-se da Geometria, tanto para a introdução dos conteúdos algébricos como para a aplicação dos mesmos na resolução dos problemas e atividades; a professora evidenciou o hábito de questionar as respostas das atividades, dando tempo para que o aluno pensasse e se posicionasse quanto ao resultado obtido, podendo explicitar para a turma qual foi a sua linha de raciocínio.

O questionamento e a correção, por parte de quem ensina, desempenham um relevante papel na aprendizagem (MOYSÉS, 2006). Nesta direção, a professora regente proporcionou questionamentos capazes de provocar o desequilíbrio na estrutura cognitiva dos alunos fazendo-os avançar para uma nova e mais elaborada reestruturação. Neste sentido, a professora ao fazer questionamentos ou interlocuções tais como: Me explique o que você pensou para resolver assim? Como você fez?Por que usou esse caminho? Nas figuras anteriores isso também acontece? Mostrou que a ação de correção não se resumiu em simplesmente indicar o erro e substituí-lo pela resposta correta, mas sim o pensar sobre a resolução.

Na opinião dos autores Ruthven; Hofmann; Mercer (2011, citados por PONTE; QUARESMA; BRANCO, 2012, p.70) nos momentos de discussão coletiva que ocorrem após a realização de uma tarefa em pequenos grupos "as intervenções da professora 
servem predominantemente para apoiar os alunos na sua articulação do pensamento matemático e para levar estrategicamente a turma a relacionar esse pensamento a exemplos, ou princípios, ou ferramentas já previamente encontrados”.

Este tipo de intervenção feita pela professora não é apenas produtivo para o aluno que explica como fez, e estabelece relações, mas também para os seus colegas, que irão comparar a sua linha de raciocínio com a que acabaram de ouvir e ainda fazer questionamentos sobre esta. Durante as observações foi possível perceber algumas das trocas feitas entre alunos, assim como entre alunos com a professora, como no diálogo referente a correção da atividade abaixo, na qual foi apresentada uma sequência. A atividade teve como objetivo identificar a regularidade e a generalização, através de uma expressão algébrica.

\section{Atividade proposta pela professora}

Observe o número de bolinhas em cada posição. Você saberia calcular quantos pontos terá na $7^{\mathrm{a}}$ posição?

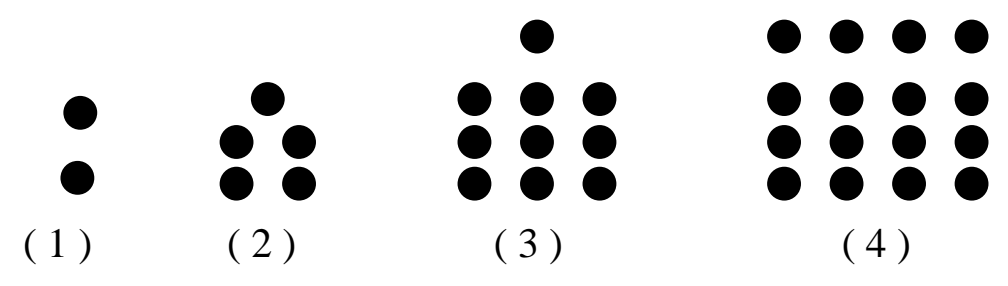

Que quantidade de bolinhas terá na posição $\mathrm{x}$ ?

\section{P: Quem conseguiu identificar a lógica desta segunda sequência?}

[Muitos alunos falam juntos. Não chegaram a uma resposta em comum.]

$\mathbf{A}_{11}$ : Na segunda figura soma 3, na terceira soma 7 ...

P: Vamos fazer uma tabela para facilitar:

\begin{tabular}{|c|c|}
\hline Figura & N. $^{\mathbf{o}}$ Pontos \\
\hline $1^{\mathrm{a}}$ & 2 \\
\hline $2^{\mathrm{a}}$ & 5 \\
\hline $3^{\mathrm{a}}$ & 10 \\
\hline $5^{\mathrm{a}}$ & \\
\hline
\end{tabular}

P: Quantos pontos teria a $5^{a}$ figura?

A11: 25

A9: 26 
P: Quem respondeu 25, como pensou?

[O aluno analisa a resposta, faz alguns cálculos e verifica que não está certa.]

$\mathbf{A}_{11}$ : Eu calculei o quadrado do número.

P: Nas figuras anteriores, a quantidade de bolinhas é o quadrado do número?

[Muitos alunos falam juntos que além do quadrado, há ainda mais uma bolinha.]

P: Quem respondeu 26, como pensou?

A9: 5 vezes 5 mais um.Depois de calcular o quadrado do número soma-se um.

A12: Dá pra ver no desenho que é o número vezes ele mesmo e mais um.

P: Exatamente! Nas figuras é possível observar essa regularidade, certo?

[Alguns alunos respondem que sim e a professora se volta para o quadro circulando a parte que possui as duas dimensões formadas pela mesma quantidade de bolinhas.]

P: Então, por essa lógica, qual será a quantidade de bolinhas na $7^{a}$ figura?

A13: 7 vezes 7 mais um?

A9: Sim, é 7 vezes 7 mais um.

P: Certo, será o quadrado de 7 mais uma unidade.

P: E se a figura fosse $x$. Na verdade não sabemos qual é o número da figura.

A: Éx vezes $x+1$

P: Podemos escrever...

A: $x^{2}+1$

Dessa forma a professora vai dialogando com a turma até que seja possível fazer o reconhecimento de uma regularidade, para então, generalizá-la através de uma expressão algébrica. Observa-se no diálogo que a professora proporcionou aos alunos pensarem sobre a resolução e que os mesmos participaram ativamente. A professora desafiou o aluno que respondeu incorretamente ao questionamento a pensar sobre o seu resultado.

Nesta direção Leinhardt; Steele (2005, citados por MENEZES; FERREIRA; MARTINHO, 2014, p. 143) ao mencionarem o momento de diálogo e partilha das explicações por parte dos alunos, "Apontam em particular para a importância do professor convidar os alunos para discutirem, para repensar suas asserções e explicarem publicamente diversas formas de pensar".

O momento da correção das atividades pode ser muito proveitoso, permitindo ao aluno um momento de expor a sua forma de resolução do problema e obter um retorno 
imediato do professor, oportunizando assim, a reconstrução de ideias, como no diálogo acima.

Ao explicar de que forma pensou para resolver o problema, o aluno precisa organizar as informações, expressar seu raciocínio de forma clara.

\begin{abstract}
Ao pedir que o aluno explique, o professor pode detectar se está havendo, no plano intrapsicológico, uma reestruturação das relações que ocorrem no âmbito interpsicológico. Para isso é necessário que o aluno consiga expor com suas próprias palavras o assunto tratado, deixando perceber possíveis relações com outros temas; que exemplifique com dados tirados do seu cotidiano; que faça generalizações; etc. (MOYSES, 2006, p. 38).
\end{abstract}

As atividades trazidas pela professora propiciaram a reflexão e o desenvolvimento do pensamento algébrico, tais como essas que envolvem padrões, permitindo uma generalização da situação apresentada. Muitas foram as atividades que apresentaram problemas na resolução, nas quais os alunos foram questionados, tornando o ambiente desafiador e investigativo, e sempre proporcionando um diálogo direcionado no qual o aluno pôde expor o que pensava. Essa interlocução é rica, quer seja entre professor e aluno ou aluno e aluno. Desta maneira é possível compartilhar ideias, aprimorá-las, pensar sobre como o colega pensa e faz, desenvolvendo novas formas de aprendizagem. Schwantes (2004, p. 501) incentiva essa discussão, que "contribui para o desenvolvimento e elaboração do pensamento algébrico.”.

Acredita-se que a busca pelo entendimento de uma situação apresentada, a qual ainda não está na linguagem algébrica, e na tentativa de traduzi-la para essa nova linguagem há um desenvolvimento e amadurecimento do pensamento generalizante e este desenvolvimento propicia um melhor aprendizado de Álgebra no qual, a linguagem tem um papel fundamental. (SCHWANTES, 2004).

Quando a linguagem é clara e acessível aos alunos, professor e aluno passam a interagir no mesmo contexto dialógico, estabelecendo-se assim a comunicação. Isto é, a linguagem tem por função estabelecer a comunicação entre os interlocutores. Nesta acepção, "O processo de ensino e aprendizagem em Matemática está diretamente ligado à forma de comunicação estabelecida em sala de aula, onde a mesma se desenvolve através da linguagem, sendo esta um aspecto central em todas as atividades humanas e, e particular, nas aulas" (FELICETTI, 2010, p.36).

Observa-se a importância do papel do professor para que as atividades propiciadas tenham um significado e, que este não seja importante apenas para obter uma aprovação 
no final de ano. Mas que o aluno seja capaz de relacionar o que aprendeu na escola com fatos de sua realidade.

Simultaneamente às observações da turma foram aplicadas atividades em três etapas que se diferenciavam pelo seu grau de dificuldade. Foi analisado o tipo de dificuldade encontrada pelo aluno na realização das atividades. Estas exigem que o aluno traduza determinadas situações-problema, apresentadas através de figuras, breves textos, sequências ou questionamentos, para a linguagem algébrica. De acordo com alguns autores há uma estreita relação entre a linguagem matemática e a língua materna, visto que, a primeira depende da oralidade da segunda. (MACHADO, 1990; MEIRA, MEDEIROS e SILVEIRA, 2015; BRASIL, 1997).

Durante as observações em sala de aula, foram aplicadas algumas atividades relacionadas com o conteúdo algébrico que estava sendo, ou já havia sido trabalhado pela professora. Essas atividades foram divididas em quatro blocos:

A Atividade 1, com o objetivo de verificar como os alunos faziam a tradução de uma situação na qual podiam visualizar os objetos que estavam sendo representados para a linguagem algébrica, esteve composta por 3 situações para as quais havia duas solicitações: a) representar simbolicamente, ou seja, através de uma expressão algébrica; b) escrever a expressão algébrica na forma reduzida.

\section{Atividade 1}

Observe as figuras ${ }^{2}$ abaixo e o símbolo que representa cada uma delas e faça o que se pede:

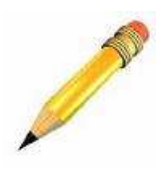

g

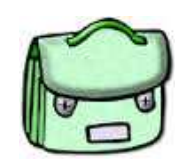

d

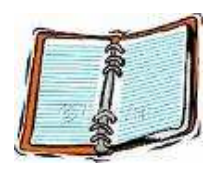

$\mathbf{a}$

a) Represente simbolicamente cada uma das situações abaixo.

b) Escreva as representações do item anterior na forma reduzida, se possível.
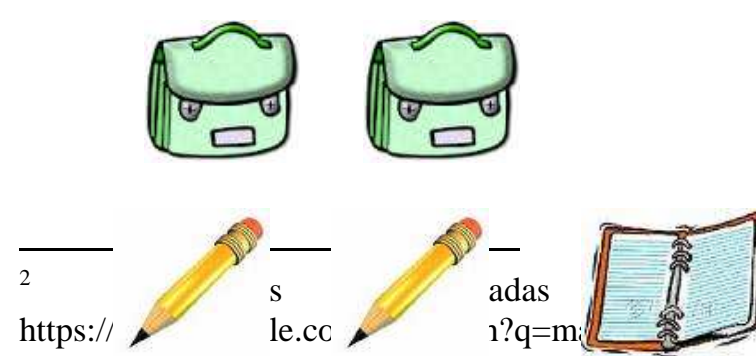

internet.

Disponível

em:

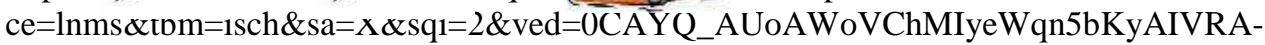

QCh3wxQ70\#tbm=isch\&q=1\%C3\%A1pisescolar 

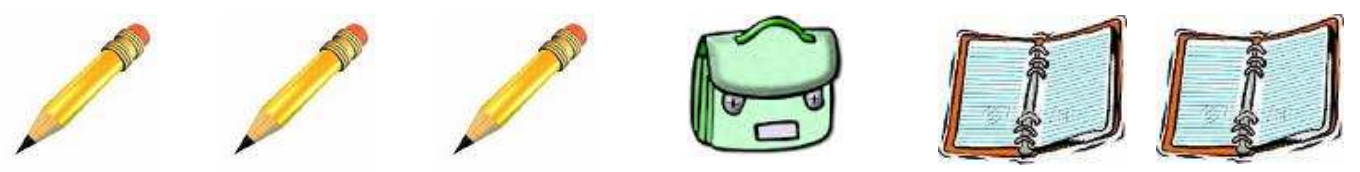

Para a solicitação no item a: representar simbolicamente cada uma das situações, foi resolvido facilmente pelos alunos, sendo obtido $100 \%$ de acertos, ou seja, eles conseguiram representar algebricamente a situação, substituindo o objeto pela letra que o representava.

$\mathrm{Na}$ segunda solicitação, ou seja, item b da mesma questão, que envolvia a forma reduzida já trabalhada em sala de aula pela professora regente, foi a seguinte: Escreva estas representações na forma reduzida, se possível, já apresentou um resultado inferior em relação à primeira questão, sendo obtidos 96,87\% de acertos. Percebe-se que a redução de uma expressão algébrica traz dificuldade já que nem sempre o resultado final corresponde a um único termo como resposta, ou seja, não terá um fechamento, podendo ser representada por uma adição ou subtração de termos, como por exemplo, o resultado encontrado na letra $\mathrm{b}$ pelo aluno $\mathrm{A}_{14}$.

Figura 1 - Resolução da atividade 1 pelo aluno $\mathrm{A}_{14}$
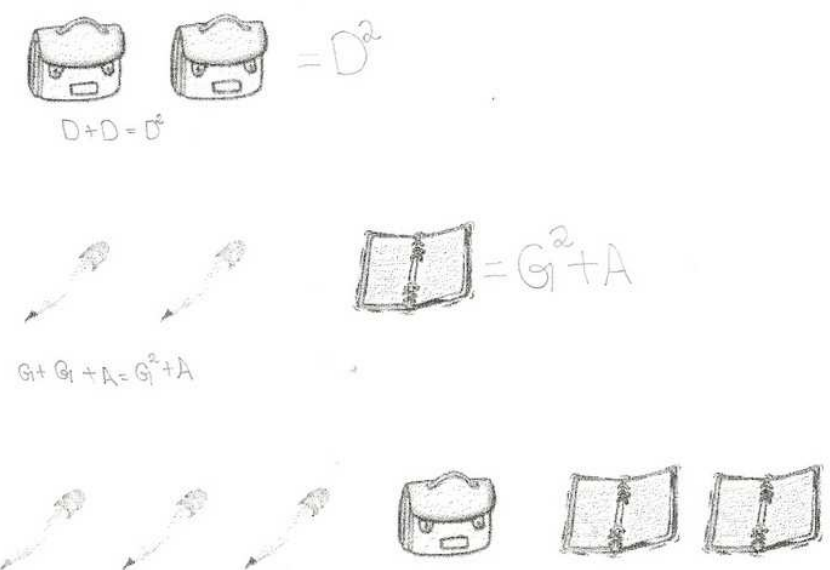

Fonte - Banco de dados da autora

$\mathrm{Na}$ primeira solicitação da atividade, apenas $\mathrm{A}_{14}$ não representou corretamente a forma reduzida das situações, fazendo uma troca nos conceitos matemáticos, tais como em $\mathrm{d}+\mathrm{d}$, onde ele representa por $\mathrm{d}^{2}$ e não $2 \mathrm{~d}$ como pode ser observado na figura 1 . 
Observa-se, ainda, que o aluno associou corretamente os objetos com a representação algébrica dada a eles, representando corretamente cada uma das situações simbólicas e que também soube que objetos, ou seja, variáveis comuns podem ser somadas, organizando-as em grupos como fez com $\mathbf{d}+\mathbf{d}, \mathbf{g}+\mathbf{g}+\mathbf{a}$ e também com $\mathbf{g}+\mathbf{g}+\mathbf{g}+\mathbf{d}+\mathbf{a}+\mathbf{a}$. No entanto, ao representar na forma reduzida ele coloca $d+d$ com resultado $\mathrm{d}^{2}$, fazendo o mesmo com $\mathrm{g}+\mathrm{g}$ e a+a, porém com $\mathrm{g}+\mathrm{g}+\mathrm{g}$ ele aponta $3 \mathrm{~g}$ como resultado. As resoluções apresentadas por esse aluno podem indicar a não apropriação da operação de multiplicação, de forma que o aluno não percebe a diferença entre utilizar um expoente ou um coeficiente em uma representação algébrica.

A Atividade 2, na qual o aluno não tinha os objetos representados para visualização, também tinha o objetivo de analisar a tradução de uma situação para a linguagem algébrica. A ideia era perceber se o fato de poder visualizar os objetos representados traz ou não facilidade para a resolução correta da atividade. A atividade esteve composta de três situações para as quais é necessário a representação simbólica.

\section{Atividade 2}

Represente simbolicamente cada uma das situações abaixo:

a) Simoni comprou duas calças neste fim de semana.

b) Fábio comprou três calças e duas camisetas.

c) A compra de Fábio mais a compra de Simoni.

A atividade 2 possui o mesmo objetivo da atividade propostas na atividade 1, diferenciando-se desta na visualização dos objetos que não estão disponíveis, mas sim em linguagem matemática traduzida para a linguagem corrente, a da oralidade. Apesar de o desempenho da turma ser considerado bom, este foi inferior ao obtido na atividade 1. Nos itens $a$ e $b$ o aproveitamento foi de $90,63 \%$ e no item $c$ de $75 \%$. Tais dados parecem indicar que o fato de visualizar os objetos a serem representados algebricamente pode tornar a representação simbólica mais fácil, como ocorreu na questão 1. Isso pode ser sinalizador da necessidade de pré-requisitos referentes a interpretação e/ou compreensão do português, mostrando-se assim, esse não domínio interpretativo como um obstáculo à aprendizagem matemática.

A Figura 2 mostra a resolução da Atividade 2 pelo aluno $\mathrm{A}_{22}$ na qual é possível observar que ele representou corretamente o solicitado na letra $a$, representando as 
calças por $x$. Porém, no item $b$ ele representa as calças e as camisetas pela mesma letra $\mathbf{x}$, errando o próximo item que solicitava a soma da compra realizada. O aluno apresentou conhecimento quanto à representação algébrica, quanto a representação da quantidade, entretanto, representou duas varáveis com a mesma letra x.

Figura 2 - Resolução da atividade 2 pelo aluno $\mathrm{A}_{22}$.

1- Represente simbolicamente cada uma das situações abaixo:

a) Simoni comprou duas calças neste fim de semana.

b) Fábio comprou três calças e duas camisetas.

c) A compra de Fábio mais a compra de Simoni.

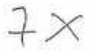

Fonte - Banco de dados da autora

O maior índice de erro, nessa questão, foi no item c: A compra de Fábio mais a compra de Simoni, em que o aluno necessita fazer uma redução das expressões encontradas anteriormente. Um dos fatores influentes na dificuldade dessa questão é o fato de a representação não ter fechamento. De acordo com Booth (1995), um erro bastante comum entre os alunos é de simplificar uma expressão como $2 \mathrm{a}+5 \mathrm{~b}$ para $7 \mathrm{ab}$. Percebe-se que o aluno não aceita $2 \mathrm{a}+5 \mathrm{~b}$ como resposta válida, existindo a dificuldade em "aceitar a ausência de fechamento" (COLLINS 3 , 1975 citado por BOOTH, 1995, p. 27).

O aluno evidencia dificuldade de entender a "ausência de fechamento", tendo em vista que, quando chega à $7^{\mathrm{a}}$ série, passou por anos de estudo no contexto aritmético no qual esta propriedade procedia. A Aritmética busca respostas numéricas, já a Álgebra é diferente, pois ela estabelece relações representando-as de forma geral e simplificada. Parte das dificuldades também se atribui à interpretação dos símbolos operatórios.

Outro fator relevante percebido na questão é a dificuldade de interpretação. $\mathrm{O}$ aluno não consegue entender o que está sendo solicitado. Não sendo capaz de interpretar, o aluno não consegue representar formalmente a situação.

A Atividade 3, que se refere a uma situação problema com figura geométrica, teve como objetivo representar o perímetro simbolicamente.

\footnotetext{
${ }^{3}$ COLLINS, Kevin F.. A study of Concrete and Formal Operations in School Mathematics: A Piagetian Viewpoint. Melbourne: Australian Council for Educational Research, 1975.
} 
Atividade 3

Qual a expressão algébrica que representa o perímetro desta figura?

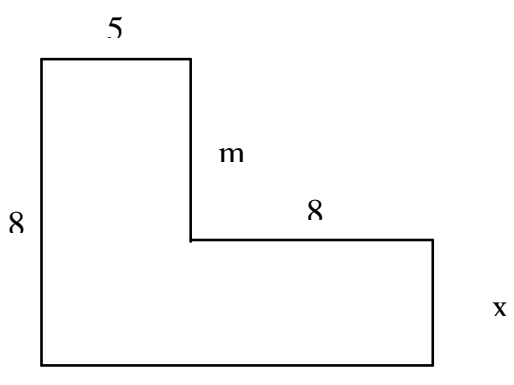

13

Essa atividade proposta, que também exige o conceito de perímetro, mostrou, assim como na questão 2, as dificuldades na ausência de fechamento com 18,75\% de erro e na interpretação, já que $12,50 \%$ dos alunos deixaram em branco. A maior parte dos alunos respondeu corretamente a questão, representando $65,63 \%$ dos alunos e, $3,12 \%$ interpretaram corretamente, mas erraram ao realizar a redução dos termos.

A Figura 3 apresenta a resolução feita por um aluno. Observa-se que o aluno indicou corretamente a soma de todos os lados da figura, demonstrando domínio do conceito de perímetro, no entanto, ele junta 34 com as variáveis m e x. Isto pode indicar a dificuldade de aceitar $34+m+n$ como resposta válida.

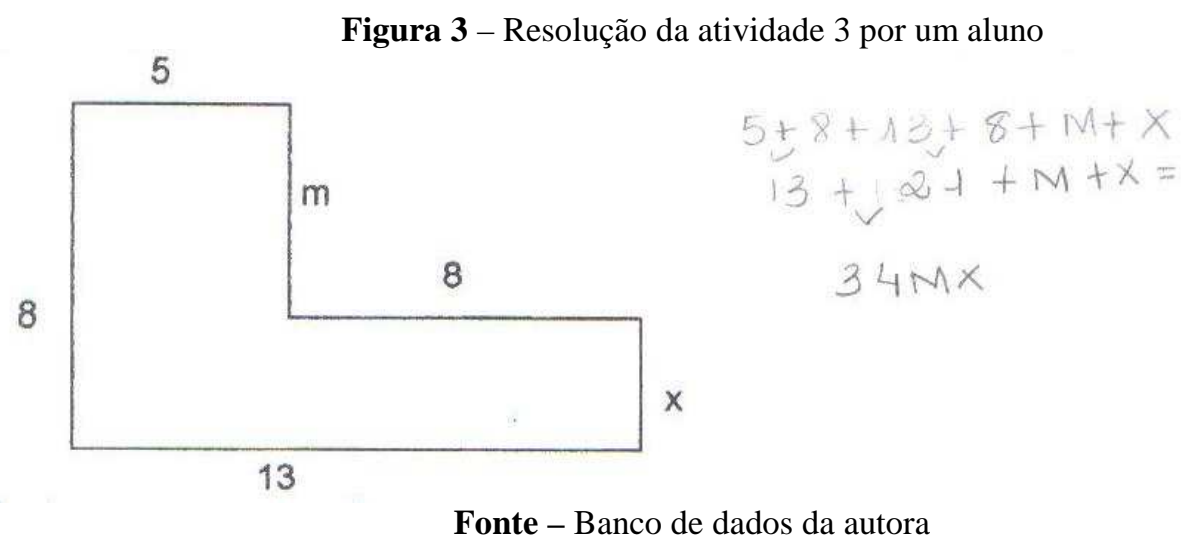

A Atividade 4, que se refere a uma sequência, teve como objetivo verificar se o aluno consegue identificar a regularidade, o padrão existente, fazer a generalização desta regularidade e, por fim, representá-la algebricamente. 


\section{Atividade 4}

Observe a sequência de triângulos ${ }^{4}$.
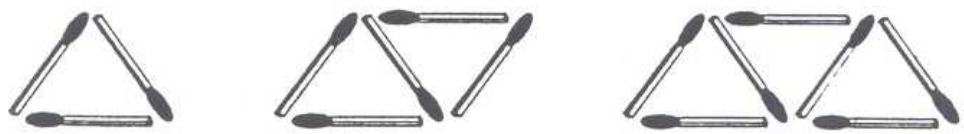

Complete a tabela com os dados referentes a esta sequência:

\begin{tabular}{|c|c|c|c|c|c|c|}
\hline $\begin{array}{c}\text { Número } \\
\text { de } \\
\text { triângulos }\end{array}$ & $\mathbf{1}$ & $\mathbf{2}$ & $\mathbf{3}$ & $\mathbf{4}$ & $\mathbf{5}$ & $\mathbf{n}$ \\
\hline $\begin{array}{c}\text { Quantidade } \\
\text { de } \\
\text { palitos }\end{array}$ & $\mathbf{3}$ & & & & & \\
\hline
\end{tabular}

Quantos palitos seriam necessários para fazer 10 triângulos?

Todos os alunos da turma tentaram resolver essa questão, mostrando habilidade em organizar as informações em tabelas. A habilidade dos alunos de organizar os dados em tabelas se deve ao fato da professora propor em aula atividades desse tipo. Do total de alunos, 59,38\% identificaram a regularidade existente na sequência, ao representá-la com a expressão algébrica $n+2$, como mostra a Figura 4 a seguir.

Figura 4 - Resolução da questão 4 por um aluno

\begin{tabular}{|c|c|c|c|c|c|c|}
\hline $\begin{array}{c}\text { Número de } \\
\text { triângulos }\end{array}$ & 1 & 2 & 3 & 4 & 5 & $n$ \\
\hline $\begin{array}{c}\text { Quantidade de } \\
\text { Palitos }\end{array}$ & 3 & 5 & 7 & 9 & 11 & $n+2$ \\
\hline
\end{tabular}

Fonte - Banco de dados da autora

Dessa forma, deduz-se que houve a percepção de que a cada triângulo a mais são necessários mais dois palitos. Os alunos que conseguiram representar corretamente em linguagem algébrica $2 n+1$, que generaliza a situação, representaram $18,75 \%$ do total. Mesmo os alunos que não responderam corretamente a última coluna da tabela, completaram-na com n +2 como mostra a Figura 4 ou com a sequência numérica, ou seja, com o número 13. Nenhum aluno deixou a última coluna em branco.

Acredita-se que há dificuldade no que se refere à abstração das regularidades que estão implícitas nas sequências. $\mathrm{O}$ fato de não abstrair a regularidade presente impossibilita o aluno de fazer a representação da mesma através da linguagem algébrica.

\footnotetext{
${ }^{4}$ Atividade adaptada de Imenes e Lellis, $6{ }^{\mathrm{a}}$ série (2002, p.195).
} 


\section{CONSIDERAÇÕES FINAIS}

São muitos os pontos que devem ser avaliados sobre as dificuldades que se tem no ensino de Álgebra. As análises realizadas nas resoluções das atividades mostram que parte das dificuldades apresentadas pelos alunos na tradução das situações apresentadas nos problemas para a linguagem algébrica, reside na interpretação. Não conseguindo formalizar as informações, o aluno não resolverá o problema. Acredita-se que grande parte da dificuldade de interpretação está relacionada com o fato de o aluno ter uma deficiência para associar a linguagem falada com a escrita. Talvez falte que seja propiciado um espaço para que os alunos escreverem as suas formas de raciocínio. Explicitando-as terão de organizar as ideias para que possam ser entendidos, desenvolvendo, assim, a linguagem. Desta forma, a explicação contribuirá para a construção do conhecimento e ainda tornará a aula mais rica com essa troca de ideias.

Além da tradução da linguagem corrente para a linguagem algébrica, a resolução de um problema exige que o aluno utilize os conhecimentos que fazem parte dos procedimentos algébricos. O estudo algébrico, que tem início na $6^{\mathrm{a}}$ série do Ensino Fundamental, e aprofunda-se na $7^{\mathrm{a}}$ série, constitui uma nova fase de aprendizagem do

aluno. É nesse momento que o educando se depara com um cenário totalmente novo e algumas vezes contraditório aos procedimentos aritméticos aos quais estava acostumado. Acredita-se que, além do estudo algébrico ser iniciado já nas séries iniciais, é necessário explorar as diferenças existentes entre esses dois campos matemáticos no que se refere aos procedimentos de resolução. Dessa forma podem-se clarificar para o aluno essas diferenças, minimizando as dificuldades encontradas.

Quando chega a $7^{\text {a }}$ série do Ensino Fundamental entende-se que o aluno tenha uma bagagem que embase e permita a continuidade do pensamento matemático mais avançado, mas nem sempre isso acontece. Observa-se a falta de pré-requisitos na Aritmética, logo, quando existe a continuidade de procedimentos aritméticos que procedem no contexto algébrico, os alunos trazem consigo as dificuldades da Aritmética. Estas dificuldades emergindo, tornam-se barreiras para o sucesso no estudo de outros tópicos matemáticos e, é hora de rever essas dificuldades, lembrando que a Matemática é um constante retomar e re(construir), já que a todo o tempo o indivíduo constrói, relaciona ideias, assim como as modifica. 
Quanto à observação das aulas, destaca-se que mesmo a professora tendo uma aula dinâmica, permeada por atividades que propiciam a reflexão e, com um diálogo direcionado nas correções de atividades e no processo de ensino e aprendizagem de Álgebra os alunos ainda apresentam dificuldades. Talvez essa constatação reforce os aspectos relacionados à necessidade de pré-requisitos, assim como, algumas dificuldades no campo aritmético que acabam se estendendo ao campo algébrico.

\section{REFERÊNCIAS}

BOOTH, Lesley R. Dificuldades das crianças que se iniciam em álgebra. In: COXFORD, Arthur F. e SHULTE, Albert P. As ideias da Álgebra. São Paulo: Atual, 1995.

BRASIL. Ministério da Educação. Secretaria de Educação Fundamental. PCN Parâmetros Curriculares Nacionais: Matemática. Brasília: MEC, 1997.

FELICETTI, Vera Lúcia. Linguagem na Construção Matemática. Revista Educação. (PUCRS. Online), v. 1, p. 31- 43, 2010.

FLICK, Uwe. Uma introdução à pesquisa qualitativa. Porto Alegre: Bookman, 2004.

INEP. Prova Brasil. Média de proficiências, 2011. Disponível em: http://download.inep.gov.br/educacao_basica/prova_brasil_saeb/resultados/2012/Saeb_ 2011_primeiros_resultados_site_Inep.pdf. Acesso em 08 jan. 2015.

INEP. Descrição dos níveis de escala de desempenho de Matemática. SAEB, 2011b. Disponível em: http://download.inep.gov.br/educacao_basica/prova_brasil_saeb/escala/2011/escala_des empenho_matematica_fundamental.pdf . Acesso em 08 jan. 2015.

LINS, Rômulo Campos; GIMENEZ, Joaquim. Perspectivas em aritmética a álgebra para o século XXI. Campinas: Papirus, 1997.

MACHADO, N. J. Matemática e Língua Materna: análise de uma impregnação mútua. São Paulo: Cortez, 1990.

MEIRA, Janeisi de Lima ; MEDEIROS, Robson André Barata de; SILVEIRA, Marisa Rosâni Abreu da. Linguagem matemática e tradução: movimentos e discussões acerca da polissemia. In: Anais da XIV Conferência Interamericana de educação Matemática, 2015. Tuxtla Gutiérrez, Chiapas.

MENEZES, Luís; FERREIRA, Rosa Tomás; MARTINHO, Maria Helena. Comunicação nas práticas letivas dos professores de Matemática. In: PONTE, João Pedro da (org.). Práticas Profissionais dos Professores de Matemática. Lisboa, 2014

MOYSÉS, Lucia. Aplicações de Vygotsky à Educação Matemática. Campinas, SP: Papirus, 2006. 
ONUCHIC, 1.; ALLEVATO, N. S. Novas reflexões sobre o ensino-aprendizagem de matemática através da resolução de problemas. In: BICUDO, M. A. V.; BORBA, M. C. (Orgs.). Educação Matemática: pesquisa em movimento. São Paulo: Cortez, 2004. p. $213-231$.

PONTE, João Pedro da; QUARESMA, Marisa; BRANCO, Neusa. Práticas profissionais dos professores de Matemática. Avances de Investigación em Educatión Matemática, vol. 1, $65-86$.

SCHWANTES, Vilson. Uma Reflexão Sobre O Desenvolvimento do Pensamento Algébrico Discente no Ensino Fundamental. In: SANTIAGO, Anna Rosa Fontella (Org.). Educação Nas Ciências: Pesquisas discentes 2003. Ijuí: Editora Ijuí, 2004. p.497-518 